\title{
'Outras ' vozes no Canadá: no Language is Neutral e outros poemas de Dionne Brand
}

\section{'Other' voices in Canadá: no Language is Neutral and other poems of Dionne Brand}

\author{
Francieli de Oliveira ${ }^{1}$
}

\begin{abstract}
Resumo
Este trabalho tem por objetivo analisar alguns poemas da escritora Dionne Brand. De origem caribenha e imigrante no Canadá, Brand discute temas socialmente polêmicos, tais como, racismo, sexualidade, feminismo e marginalização. Assim, selecionamos alguns de seus textos de forma a analisarmos o conteúdo para a verificação se esses problemas são refletidos em sua linguagem como escritora. Considerando-se que Brand é negra, imigrante e mulher, sua poesia reflete uma posição hifenizada, expressa na escolha de temas que remetem ao Caribe, no estilo e na linguagem que envolve o uso do 'demótico' como forma de resistência às diversas opressões que imigrantes caribenhos ainda sofrem no Canadá, país que adota oficialmente a política do multiculturalismo.
\end{abstract}

Palavras-chave: Multiculturalismo. Canadá. Hífen. Poesia.

\begin{abstract}
This work aims the analysis of some of Dionne Brand's poems. Caribbean and an immigrant in Canada, Brand discusses social polemics issues, such as racism, sexuality, feminism, and marginalization. Thus, we selected some texts to analyze its content and verify if these problems are reflected in her speech as a writer. Considering that Brand is black, immigrant and woman, her poetry reflects a hyphenated position, it express in its content relation to Caribbean, in her style and language that evolves the 'demotic' used as resistance ways for many oppressions that Caribbean immigrants still suffer in Canada, country which has adopted the multiculturalism politics.
\end{abstract}

Keywords: Multiculturalism. Canada. Hyphen. Poetry.

\section{Introdução}

Teorias culturais contemporâneas (HALL, 1990; BHABHA, 2004) sustentam que aquilo a que denominamos identidade cultural são processos sujeitos à contínua transformação. Sempre condicionais, as identidades são as negociações entre discursos, práticas e posições que tanto podem se compatibilizar quanto antagonizar. Em outras palavras, identidades são posicionamentos que o sujeito é levado a tomar e negociar diante de histórias, lugares, tempos e culturas específicas e que, em especial na contemporaneidade, estão vinculadas a circunstâncias tais como os processos globais de colonização, imigração e diásporas.

\footnotetext{
${ }^{1}$ Graduada em Letras Inglês pela Universidade Estadual do Centro-Oeste - UNICENTRO. Especialista em Ensino de Línguas Estrangeiras e mestranda em Estudos da Linguagem pela Universidade Estadual de Londrina. E-mail: fran_oliveira_23@ hotmail.com
} 
São esses fenômenos que, ocasionando inúmeras formas de ruptura, tanto têm perturbado o caráter relativamente 'estabelecido' de um número de povos e indivíduos. Assim, considerando-se que identidades são 'situadas' em histórias específicas, pergunto quem é a escritora e ativista política Dionne Brand? De que posição ela fala?

Brand é um dos nomes que se destacam na literatura canadense contemporânea. Nascida em Trinidad Tobago no Caribe em 1953, mudou-se aos quatro anos de idade para o Canadá, onde vive até hoje. Apesar da mudança de país, Brand manteve contato com o Caribe, por meio de textos produzidos por e sobre a comunidade caribenha oprimida e que buscava a independência. Dessa forma, em certo momento de sua vida, ela acaba por se envolver em movimentos libertários e contra as opressões raciais. Embora, conforme Brand declara em entrevista à Poets Talk, nos dias atuais, a escritora não mais faça parte desses projetos, ela reafirma ainda ser necessário dar-se voz aos oprimidos. Assim, embora a própria Brand afirme ter optado por aquelas influências que lhe "permitissem obter integridade, futuro e visão" (BUTLING; RUDY, 2005, p. 69), a obra de Brand tem como base contextual o anticolonialismo e o Black Nationalism do Caribe, movimentos que ela admira profundamente. Como mulher, negra e imigrante, Brand discute questões socialmente polêmicas, tais como, racismo, sexualidade, lesbianismo, entre outras. Este trabalho tem como objetivo analisar de que modo Brand, como poeta 'engajada' a essas importantes discussões, articula em seus poemas estratégias de resistência às diversas opressões que permeiam a vida daqueles que estão à margem da nação. Essa forma de resistência é bastante visível na escolha que ela faz de temas, estilo e linguagem. Considerandose este objetivo e para um melhor entendimento da posição de Brand, a seguir, apresentamos um breve contexto político e cultural canadense.

\section{O Canadá, Identidades e o Multiculturalismo}

Conforme David Taras argumenta, "há, ao longo de toda a história do Canadá, uma paixão por identidade" (apud KAMBOURELLI, 1996, p. 9, tradução nossa). No entanto, não existe uma clareza quanto a essa identidade, uma vez que, colonizado pela França e Inglaterra, duas grandes potências europeias no século dezoito, o Canadá testemunha hoje rivalidades entre essas duas 'nacionalidades' invasoras. Além dessa histórica rivalidade, a presença de grande número de imigrantes e seus descendentes torna claro que outras 'nacionalidades', também, contribuíram para a formação do estado-nação. Referindo-se a esse panorama nacional complexo, Scott MacKenzie, citando Charles Levin, refere-se ao Canadá como o primeiro Estado não somente pós-nacional, mas, também, codependente, "no qual cada nação precisa das outras para a preservação de sua própria identidade que é fraturada e tênue" (MACKENZIE, 2004, p. 20, tradução nossa).

Se, por um lado, o reconhecimento de ser o Canadá uma nação originalmente colonizada por franceses e ingleses levou à formação de um Estado oficialmente 'bicultural' e 'bilingue', o reconhecimento de sua pluralidade étnica levou, a partir dos anos 70, ao estabelecimento de uma política multiculturalista, cuja expressão maior é o Multiculturalism Act de 1988 e que tem os seguintes objetivos expressos:

É declarado que a política do governo do Canadá: "Reconhece e promove o sentido de que o multiculturalismo reflete a diversidade cultural e racial do Canadá e o conhecimento do direito social de todos os cidadãos à preservação, fortalecimento e partilha de sua herança cultural [...].” (PATRIMOINE CANADIEN, 2008, tradução nossa).

No entanto, o multiculturalismo tem sido objeto de debates e as opiniões sobre ele vão desde a idealização até a absoluta descrença. Linda Hutcheon 
argumenta que o multiculturalismo, "se ainda não é completamente realizado, é um modelo de inovação apropriado para a nossa sociedade pluralmente democrática" (HUTCHEON; RICHMOND, 1991, p. 15, tradução nossa). Ela também afirma que o multiculturalismo é uma forma de se permitir "às muitas vozes contemporâneas do Canadá o acesso às condições culturais e materiais, possibilitandolhes falar e serem ouvidas" (HUTCHEON; RICHMOND, 1991, p.16, tradução nossa).

Se Hutcheon, embora reconhecendo as limitações do multiculturalismo, é otimista em relação às possibilidades dessa política de reiterar a igualdade entre os cidadãos canadenses, para Neil Bissoondath, ele é apenas uma forma de enfatizar a diversidade entre os diversos grupos étnicos, sem, no entanto, reconhecer as profundas interações e relações antagônicas que surgem dessa pluralidade. O multiculturalismo, assim, é para ele uma "psicologia de separação" (BISSONDATH, 2002, p. 100).

As opiniões divergentes sobre o multiculturalismo refletem as diversas formas de se pensar e interpretar o conceito. Em A Border Within, o filósofo e cientista político Ian Angus observa que o conceito de multiculturalismo pode ser considerado como um fator sociológico. Nesse caso, o termo refere-se ao fato de o país ser formado por uma pluralidade de grupos étnicos. O termo multiculturalismo, também, pode ser aplicado à política governamental instituída no Canadá, a partir dos anos de 1970, pelo então primeiro ministro Pierre Trudeau. Finalmente, o termo pode ser considerado, do ponto de vista ideológico, como um "ideal social" (ANGUS, 1997, p. 6, tradução nossa) ou seja, como o modo pelo qual o Estado e seus cidadãos deveriam se portar em relação à diversidade étnica.

Embora Angus (1997) reconheça a possibilidade de ligação entre essas diferentes formas de se interpretar o termo multiculturalismo, ele, também, observa que essa conexão não é automática e tem importantes implicações. Entre essas implicações, o autor cita como exemplo a possibilidade de a pluralidade étnica gerar preocupação com o estabelecimento de uma política homogeneizadora voltada para a identificação com "o que temos em comum" (ANGUS, 1997, p. 6), em vez do ideal social que para ele é baseado no reconhecimento e aceitação das diferenças. Assim, para o escritor, o que deve prevalecer para se atingir o ideal social é "identidade e diferença" e não "identidade ou diferença” (ANGUS, 1997, p. 6, tradução nossa).

Da complexa relação entre os conceitos de identidade e diferença, surge um espaço ambivalente, o do hífen que, muitas vezes, é representado visivelmente em diversas expressões gentílicas. Para o escritor Fred Wah, "a marca hifenizada da identidade canadense, cuja primeira parte refere-se ao país ou continente de origem (ítalo-canadense, afro-canadense), bem como à religião (judeu-canadense), é encorajada pela política do multiculturalismo." (WAH, 2000, p. 106) O hífen é, portanto, um espaço ambivalente no sentido de que, ao mesmo tempo em que permite o acesso e manutenção de uma identidade étnica, cultural ou religiosa, é, também, habitado pela noção de que essas identificações estão submissas a uma identificação maior, a identidade cívica.

Wah, ele próprio de origem chinesa e europeia, relata que se viu compelido a assumir as "hipóteses e confusões sobre identidade [...]", concluindo que o "hífen é um espaço marcado (ou não) que tanto une quanto divide." (WAH, 2000, p. 72). Nas palavras de Wah, "estando no meio, mas não no centro", o hífen é uma ferramenta que serve tanto para "compor diferenças como para enfatizar semelhanças.” (WAH, 2000, p. 7.).

Em suas obras, Brand articula sua posição hifenizada de diversas formas, por meio da escolha de temas que remetem não somente a Trinidad, seu país de origem, mas a outros locais no Caribe; pelo estilo e linguagem que a coloca próxima de seu público alvo que é a audiência negra, historicamente marginalizada. Visando, principalmente, a essas 
comunidades oprimidas pobres de envolvimento, segundo ela, Brand traz à tona as lutas políticas em sua terra natal. Fazemos a seguir uma breve planificação dessa condição.

\section{Contextualizando o Poema e a Voz de Dionne na Luta}

Em Poets Talk, Brand, referindo-se ao papel da poesia, afirma que esta possibilita ao escritor mostrar seus sentimentos, não de uma forma mecânica, como um simples cidadão, mas como autor de uma obra artística. Essa arte engajada permite ao poeta, em um nível altamente emocional, exprimir-se sobre questões políticas e sociais de relevância (BUTLING; RUDY, 2005, p. 70). É dessa forma emocional que Brand traz à tona figuras e eventos que foram marginalizados historicamente. No poema Phyllis, Brand introduz a personagem Phyllis Coard. Originária da Jamaica, Coard foi assistente Social, professora da Universidade das Índias Ocidentais e ex-ministra para assuntos femininos em Grenada, uma ilha nação no Caribe.

Phyllis foi, após a invasão americana a Grenada em 1983, acusada de assassinato e julgada por um tribunal internacional altamente político que a condenou à pena capital, sentença que foi transformada em prisão perpétua. Sendo a única prisioneira mulher e não nativa de Grenada, Phyllis sofreu constantes abusos físicos e morais, tendo sido reclusa por volta de sete ou oito anos em uma cela solitária. Em 2000, após dezesseis anos na prisão, Phyllis foi diagnosticada como portadora de câncer de cólon, tendo sido liberada para tratamento em sua terra natal, a Jamaica.

\section{Phyllis}

Phyllis, quite here, I hear from you

not even from your own hand in a note

but from some stranger who dragged it

from a prison wall, a letter running

like a karili vine around Richmond Hill
Phyllis, I know they treat you bad

like a woman

I know is you one there and I

never forget how one night you give

me a ride in your car

and I never forget your laugh like a bronze bauble hanging in that revolutionary evening

Phyllis, when you sit down and explain

the revolution, it did sound sweet and it

did sound possible.

Phyllis, quite hear, I hear how

you so thin now, but still strong

your voice refusing departures and

soldiers cursing, your voice ringing through

bars with messages to keep up the struggle

now buried in death bed and prison wall,

I know they treat you bad

like a woman

called you hyena, a name enjoining

you alone to biology and not science,

you should have known

the first thing they would jump on

was the skill of your womb

Phyllis I remember your laugh, luminous

and bubbling in the flaming dark evening

and the moment after, your eyes serious,

searching for you glasses.

Girl, how come is quite here I hear from you, sitting in these rooms, resenting this messenger, out here, I listen through an upstart castigate

Fidel, scraping my chair to interrupt him,

just to see if you send any explanations,

I know they treat you bad

like a woman

you bewitched in their male dramas, 
their comes and their tay tay,

you, toundered, as Bernard said, in all

the usual last minute domestic things

a housewife has to do

Phyllis, they said you defied the prison guards

and talked through their shouts to be quiet

your laugh clanging against the stone walls

you look silencing soldiers.

\section{For Phyllis Coard}

Minister of Women's Affairs in the People's

Revolutionary

Gov't. of Grenada, 1979-1983, now imprisoned at Richmond

Hill Prison in Grenada for her in a coup (BRAND,

1998a, p. 8-10).

Ativista política que, a princípio, se recusa a abandonar Grenada e cuja voz ecoa com mensagens para que se mantenha a luta, nem a prisão silencia Phyllis. Sem discutir o mérito do julgamento de Phyllis e as questões políticas como a participação dos Estados Unidos no processo que culminou com a prisão da ativista jamaicana, o eu poético questiona os mal tratos que são imputados a Phyllis, por ser a única mulher na prisão.

\section{Analisando}

O poema enfatiza, portanto, que as razões para as torturas a Phyllis transpõem as fronteiras políticas, pois se tratam de fato de preconceitos raciais e sexuais, fato esse que pode ser contemplado nos versos I know they treat you bad llike a woman', called you hyena ${ }^{3}$. A primeira frase representa a discriminação pela sexualidade. Embora esses preconceitos não mais se sustentem, pois se baseiam em pressupostos biológicos ultrapassados e que se opõem à ciência, os discursos racistas ainda têm grande poder e Phyllis é comparada a uma hiena pelos guardas da prisão, representando então a discriminação racial. Mas sua voz é capaz de silenciar os próprios guardas da prisão.

Somando-se ao tema escolhido, o tom conversacional do poema sugere uma proximidade entre o eu poético e Phyllis. Como somente o eu poético possui voz, o poema confirma finalmente o silenciamento da figura marginalizada de Phyllis. O tom, também, sugere uma proximidade ambivalente, um espaço hifenizado entre Phyllis e a persona, quando consideramos o uso das expressões "quite here" and "there". Essas expressões sugerem um deslocamento. A persona do poema parece estar perdida, here ... there ... where is home? Onde é meu lar? Aqui ou lá, próxima a Phyllis no Caribe?

Phyllis, também, apresenta uma das características mais marcantes dos poemas de Brand, o uso da linguagem como uma estratégia de contestação das relações de poder que posicionam imigrantes negros caribenhos como inferiores. É notório, em seus poemas, o uso do que Mary Louise Pratt denomina code-switching, uma estratégia que representa "o poder de dominar a linguagem e não ser dominado por ela" (PRATT apud WAH, 2000, p. 82). A própria Brand comenta sobre o poder da linguagem, em entrevista à Poets Talk. No início de sua carreira, havia muitas discussões políticas entre os imigrantes caribenhos sobre que língua utilizar: "[...] nós poderíamos", diz ela, "escrever no demótico, no inglês padrão [...]." (BUTLING; RUDY, 2005, p. 71). O demótico é linguagem usualmente utilizada por imigrantes negros, em contraposição ao inglês tradicional. Assim, por violar e causar uma ruptura na linguagem dominante, o demótico tenta construir um senso de diferença, tornando-se uma forma de contato entre os escritores e uma audiência específica negra. Como Brand afirma, "não se trata de uma questão de entendimento por parte de outras pessoas," [...] a questão é o entendimento por parte da audiência alvo. Entre as obras que enfatizam o papel central da

\footnotetext{
${ }^{2}$ Eu sei que eles te tratam mal/ como uma mulher (tradução nossa).

${ }^{3}$ Te chamaram de hiena (tradução nossa).
} 
língua, como estratégia de poder, está No Language is Neutral, na qual se pode perceber o uso que a autora faz do demótico.

Is steady trembling I trembling when they ask me my name and say I too black for it. Is steady hurt I feeling when old talk breed, the sea don't have branch you know darling. Nothing is a joke no more and I right there with them, running for the train until I get to find out my big sister just like to run and nobody wouldn't vex if you miss the train, calling Spadina Spadeena until I listen good for what white people call it, saying I coming just to holiday to the immigration officer when me and the son-of-a-bitch know I have labourer mark all over my face. It don't have nothing call beauty here but this is a place, a gasp of water from a hundred lakes, fierce bright windows screaming with goods, a constant drizzle of brown brick cutting dolorous prisons into every green uprising of bush. No wilderness self, is shards, shards, shards, shards of raw glass, a debris of people you pick your way through returning to you worse self, you the thin mixture of just come and don't exist (BRAND, 1998a, p. 26).

Nos versos acima, o demótico é articulado, por meio de uma ruptura com a 'gramática' de um inglês 'padrão'. Repetições, pontuação inconvencional, sujeitos e verbos ausentes lembram o inglês oral e, ao mesmo tempo, sugerem o deslocamento do eu poético, imigrante na nova terra. As primeiras linhas descrevem os problemas com a imigração, mais especificamente, do racismo do agente da imigração. É, principalmente, nos primeiros versos que podemos observar a questão dos preconceitos raciais sofridos pela persona do poema. Perguntada sobre seu nome, a persona responde ao agente da imigração. Este argumenta que ela é muito negra para isso, para possuir um nome. Esse questionamento da identidade, a partir do nome da persona, é sugestivo de que a discriminação é tanta que a pessoa negra não tem sequer o direito à identidade. Além da discriminação racial, o eu poético experimenta a fragmentação de sua identidade "Shards, shards, shards", a persona repete. Fragmentado e deslocado, o eu poético vive a ambivalência de estar no novo lar, mas não existir. A persona experimenta a invisibilidade. $\mathrm{O}$ eu fragmentado é uma constante no poema a seguir.

You can hardly hear my voice now, woman, but I heard you in my ear for many years to come the pink tongue of a great shell murmuring and yawning, muttering tea, wood, bread, she, blue, stroking these simple names of habit, sweeter and as common as night crumbling black flakes of conversation to sleep, repetitious as noons and snow up north, the hoarse and throaty, I told you, no milk, clean up.

You can hardly ever hear my voice but $i$ heard you in my sleep big as waves reciting prayers so hourly the heart rocks to its real meaning. saying, we must make a sense here to living, this allegiance is as flesh to bone but older and look, love, there are no poems to this, only triangles, scraps, prisons of purpled cloth, time begins with this gestures, this sudden silence needs words instead of whispering

You can hardly hear my voice by now but woman I felt your breath against my cheek in years to come as losing my sight in night's black pause, I trace the pearl of your sweat to morning, turning as you turn, breasts to breasts mute prose we are a leaping, and no more may have passed here except also the map to coming home, the tough geography of trenches, quarrels, placards, barricades (BRAND, 1998a, p. 37-39).

A pontuação não convencional do poema permite leituras complexas. Retomando a questão da linguagem, a ausência de uma pontuação precisa permite que se leia o poema de uma forma contínua, o que lembra o murmúrio da concha e que também 
sugere um tom de oração. O poema em si parece uma forma de prece, tal como a própria prece que as ondas recitam na segunda estrofe. Insistentes, as ondas continuamente batem nas rochas. O que são essas ondas senão a própria memória do Caribe? A concha já remete ao mar por si só, mas o ruído emitido por ela traz não somente uma lembrança, mas o som real do mar. De lá ausente, o mar e a concha são, literal e metaforicamente, uma forma de ligação e de separação, um hífen, entre o eu poético e a personagem anônima do poema.

Do hífen emerge uma identidade fragmentada muito comum aos indivíduos e povos submetidos aos processos globais de colonização, migrações e diásporas, e que torna difícil determinar as verdadeiras lealdades. Esse sentido de fragmentação demanda do eu poético que "se faça um sentido de viver aqui," (tradução nossa) embora não haja clareza se este 'aqui' é o Caribe ou o Canadá. Nem lá, nem aqui, somente restam as lembranças, os gestos de memória, a necessidade de se romper o súbito silêncio com palavras, não com sussurros.

Ao se falar em identidade caribenha, os gestos de memória são bastante significativos. Se considerarmos as possibilidades das ondas a que o eu poético se refere serem metaforicamente as memórias que continuamente afloram, então, o mar torna-se ainda mais significativo. Ele é o hífen que ao mesmo tempo une e separa o eu poético e o Caribe. O mar traz à luz memórias de uma diáspora mais recente. Porém, o mar é também o hífen que une e separa, da mãe África, povos de origem africana espalhados pelo mundo. Assim, o mar traz as memórias não somente de uma diáspora recente, mas de toda uma história de diásporas que tem início com o processo de escravização de povos africanos. São histórias esquecidas, laços desfeitos, conexões perdidas.

Se há somente "triangles, scraps, prison purpled cloth”, (BRAND, 1998a, p. 38); portanto, só existem fragmentos e que geram fragmentos de memória. Que mapas, então, utilizar para um retorno ao lar, quando já não se sabe onde exatamente ele fica. E, mesmo na possibilidade de retorno, será ele o mesmo lar deixado há muitos anos? Será a África a mesma de antes de todas as diásporas? Será, o Caribe, o mesmo? Não. Conforme estes versos de No Language is Neutral sustentam, os mapas foram apagados pela "though geography of trenches, quarrels, placards, barricades.” (BRAND, 1998a, p. 39).

Ao evocar as memórias do Caribe, os poemas de Brand apresentam profundas imagens visuais, com um denso colorido e ênfase às cores quentes, amarelas, vermelhas e todas as suas nuances que contrastam com os tons com que ela, no poema a seguir, descreve Toronto durante o Natal. Assim como o Ano Novo, o Natal pode significar um novo período, a renovação de sonhos e conquistas. Podemos, então, pensar nesse poema como um hífen. O Natal remete ao recomeço como uma imigrante em um país desconhecido. Este é um eterno recomeço, de uma pessoa que se encontra num lugar diferente daquele que é seu, com outros costumes. Nem sempre é um processo fácil, a adaptação ao novo mundo em que se encontra. Há uma dúvida sobre o que há de vir, sobre tudo que se reinicia na vida do personagem. E como diz o poema, então, se "finge que nada nos muda" (tradução nossa), mas, na verdade, existe sim a mudança. A passagem de músicas que cantávamos, quando éramos crianças, carrega consigo a lembrança de uma vida que já passou, mas essa lembrança traz consigo a saudade desse lugar e desses momentos vividos. Observe, no poema, esses elementos.

I walk Bathurst Street until it come like home
Pearl was near Dupont, upstairs a store $r$

Christmas where we pretend as if nothing change we, make rum punch and sing, with bottle and spoon, song we weself never even sing but only hear when we was children. Pearl, squeezing her big Point Fortin self along the narrow hall singing Drink a Rum and a ... Pearl, working nights, cleaning, Pearl beating books at her age, Pearl dying back home in a car crash twenty years after everything was squeezed in, 
a trip to Europe, a condominium, a man she suckled

like a baby. Pearl coaxing this living room with a voice half lie and half memory, a voice no room nowhere could believe was sincere. Pearl hoping this room would catch fire above this frozen street. Our singing parched, drying in the silence after the chicken and ham and sweet bread effort to taste like home, the slim red earnest sound of long ago with the blinds drawn and the finally snow for Christmas and the mood that rum in a cold place takes. Well, even our nostalgia was a lie, skittish as the truth these bundle of years (BRAND, 1998a, p. 27).

\section{Conclusão}

Ao finalizar este trabalho, gostaríamos de retomar alguns dos pontos discutidos acima e ressaltar, assim, a importância de Brand na literatura canadense contemporânea. Seus poemas são ricos em imagens visuais, plenos de metáforas que nos remetem de forma bastante incisiva ao Caribe e que nos mostram costumes passados. As lembranças caribenhas, que são frequentes na obra de Brand, não constituem, porém, uma simples coletânea de memórias. Elas dão ênfase à ideia de fragmentação que é marcante nos poemas analisados. As memórias enfatizam que a figura do imigrante no poema é, em especial, a de um sujeito em trânsito, uma figura marginal, hifenizada.

A apresentação de figuras marginalizadas e hifenizadas, como nos poemas aqui analisados, é uma das características marcantes da obra de Brand e é a forma que a autora se utiliza para mostrar a resistência. $\mathrm{O}$ uso constante dessas figuras, em especial das figuras históricas com lealdades complexas, demonstra que ela, apesar de não mais participar ativamente de movimentos libertários, ainda se preocupa com problemas como os preconceitos raciais e sexuais que são mascarados pelas políticas multiculturalistas. A escritora luta, por meio de seus poemas, para que mulheres e pessoas consideradas de 'outras' raças e que sempre foram discriminadas, tenham o seu reconhecimento social.

A preocupação com os problemas enfrentados pelas pessoas socialmente marginalizadas, também, se reflete na linguagem que Brand utiliza em seus poemas e na sua utilização consciente do demótico, da linguagem do povo caribenho. O demótico é, então, utilizado como uma forma de aproximação entre autora e imigrantes caribenhos no Canadá. Considerando-se os pontos aqui discutidos, podemos definir a poesia de Brand como exemplo de literatura engajada, na qual, a arte está a serviço da luta pela transformação social. É nesse aspecto que reside a beleza da obra de Brand, que é hoje uma das mais notáveis escritoras canadenses.

\section{Referências}

ANGUS, I. A border within. Montreal: Mc GillQueen's University Press, 1997.

BHABHA, H. The location of culture. New York: Routledge, 2004.

BISSONDATH, N. Selling illusions: the cult of multiculturalism. Toronto: Penguin Books, 2002.

BRAND, D. No language is neutral. Toronto: McClelland \& Stewart, 1998a.

. Whose gaze, and who speaks for whom. In: _ Bread out of stone. Toronto: Vintage Canadá, 1998b.

BUTLING, P.; RUDY, S.. Poets talk: Conversations with Robert Kroetsch, Daphne Marlatt, Erin Mouré, Dionne Brand, Marie Annharte Baker, Jeff Derksen and Fred Wah. Alberta: University of Alberta, 2005.

HALL, S. Cultural identity and diaspora. 1990. Disponível em: <www.lwbooks.co.uk/ ReadingRoom/public/IdentityDiaspora.pdf $>$. Acesso em: 4 abr. 2008.

HUTCHEO, N.; RICHMOND, M. Other solitudes: multicultural fiction and interviews. Toronto: OUP, 1991. 
KAMBOURELLI, S. Making a difference. Cary, North Carolina: Oxford University Press, 1996.

MACKENZIE, S. Screening Québec: quebecois moving images, national identity, and the public sphere. Manchester: Manchester University Press, 2004.

PATRIMOINE CANADIEN. Multiculturalisme a été transféré multiculturalism has moved. Disponível em: <http://www.canadianheritage. gc.ca/progs/multi/ policy/act_e.cfm> Acesso em: 15 de julho de 2008 .

WAH, F. Faking it: poetics and hybridity. Ontario: NeWest Press, 2000. 
